\title{
DMOD-A mathematical model of reward and aversive nonreward in appetitive learning situations: Program and instruction manual
}

\author{
HELEN B. DALY and JOHN T. DALY \\ State University of New York, Oswego, New York
}

\begin{abstract}
A new mathematical model of the role of reward and aversive nonreward in appetitive learning situations can successfully account for over 30 appetitive learning phenomena (see Daly \& Daly, 1982). Due to the interest shown in the computer program used to simulate predictions of the model (called DMOD), we include here: (1) a copy of the program written in MICROSOFT BASIC (modifiable for similar BASIC languages used on machines such as the Apple II and TRS-80); (2) a description of the model; (3) instructions on how to conduct simulations; and (4) three simulation examples. The same program may be used to simulate predictions of the Rescorla and Wagner (1972) model in both primary and secondary reinforcement experiments.
\end{abstract}

A recently developed mathematical model of appetitive learning called DMOD can account for over 30 basic leaming phenomena (Daly \& Daly, 1982). It can simulate such basic phenomena as acquisition on a continuous or partial reinforcement schedule, blocking, and discrimination learning, as well as several paradoxical reward effects, such as the partial reinforcement acquisition and extinction effects, depression and elation effects, overleaming extinction and reversal effects, and complex phenomena such as secondary or conditioned reinforcement and acquisition of a preference for predictable over unpredictable rewards ("observing response").

Due to the interest shown in the computer program and the number of requests for help in using it, we include in this paper a brief description of the model, a manual on how to conduct simulations, and a listing of the computer program, written in MICROSOFT BASIC. The program is written to be transported with minor modifications to machines using similar BASIC languages, such as those used on the Apple II and TRS-80 Model III microcomputers.

\section{DESCRIPTION OF DMOD}

DMOD was developed to account for both trial-bytrial changes and asymptotic levels of behavior in discretetrial, appetitive learning situations. It is assumed that there are three important goal events possible that organisms learn about in appetitive learning situations. If a positive reward, such as food for a hungry organism,

The first author is supported by a National Institute of Mental Health Grant MH33497. Requests for reprints should be sent to Helen Daly, Department of Psychology, or to John Daly, Department of Mathematics, State University of New York, Oswego, New York 13126. is present, the organism learns to approach the goal. If the organism has learned to expect food and no food is present, the organism learns to avoid the goal because nonreward in the presence of an expectancy for reward is considered an aversive goal event (see Amsel, 1958, and Daly, 1974, on frustration theory). If a food reward occurs after the organism has learned to expect aversive nonreward, the organism learns to approach the goal despite the expectation of the aversive event (see Amsel, 1958 , on counterconditioning).

The Rescorla-Wagner (1972) modification of the linear operator equation (Bush \& Mosteller, 1955) is used to calculate the approach $\left(\mathrm{V}_{\mathrm{AP}}\right)$, avoidance $\left(V_{A V}\right)$, and counterconditioning $\left(V_{C C}\right)$ gradients: $\Delta \mathrm{V}=\alpha \beta(\lambda-\overline{\mathrm{V}})$. The symbols represent the following: $\mathrm{V}$-strength of the gradient due to prior learning; $\overline{\mathrm{V}}$-sum of the gradient strengths of all stimuli present [it is assumed that learning to a given stimulus is influenced by the associative strength of all stimuli present (Rescorla \& Wagner, 1972, p. 76)]; $\Delta \mathrm{V}$-change in associative strength on a given trial; $\alpha$-salience of the stimulus [each stimulus has its own $\alpha$ level $(0<\alpha \leqslant 1) ; \beta$-learning-rate parameter [determined by the vigor of the goal response or hunger drive if food is the goal event for conditioning of $\left.\mathrm{V}_{\mathrm{AP}}(0<\beta<1)\right]$; and $\lambda$-magnitude of the goal event. These definitions were adopted from the Rescorla-Wagner (1972) model (RWMOD). RWMOD, however, allows for only one $\lambda$, which varies from 0 to 1 as a function of the size of the goal event or unconditioned stimulus (e.g., food reward), and only one V value is conditioned. Three goal events, each with its own $\lambda$ level, are possible in DMOD, and each one conditions a different $V$ strength. To condition $V_{A P}$, the size of $\lambda$ is determined by the size of the reward given (e.g., amount of food). If the $\lambda$ value is greater than $\bar{V}_{A P}$, the change in $V_{A P}$ is positive and the approach gradient increases (see Table 1, upper left equation, 
Table 1

DMOD: Equations Used to Calculate Changes in V Strength

\begin{tabular}{|c|c|c|c|}
\hline Trial & Approach $\left(\mathrm{V}_{\mathrm{AP}}\right)$ & Avoidance $\left(\mathrm{V}_{\mathrm{AV}}\right)$ & Counterconditioning $\left(\mathrm{V}_{\mathrm{CC}}\right)$ \\
\hline $\begin{array}{l}\text { Food } \\
\text { No-Food }\end{array}$ & $\begin{array}{l}\Delta \mathrm{V}_{\mathrm{AP}}=\alpha \beta_{\mathrm{I}}\left(\lambda-\overline{\mathrm{V}}_{\mathrm{AP}}\right) \\
\Delta \mathrm{V}_{\mathrm{AP}}=\alpha \beta_{\mathrm{D}}\left(0-\overline{\mathrm{V}}_{\mathrm{AP}}\right)\end{array}$ & $\begin{array}{l}\Delta \mathrm{V}_{\mathrm{AV}}=\alpha \beta_{\mathrm{D}}\left(0-\overline{\mathrm{V}}_{\mathrm{AV}}\right) \\
\Delta \mathrm{V}_{\mathrm{AV}}=\alpha \beta_{\mathrm{I}}\left[2\left(0-\mathrm{V}_{\mathrm{AP}}\right)-\overline{\mathrm{V}}_{\mathrm{AV}}\right]\end{array}$ & $\begin{array}{l}\left.\Delta V_{C C}=\alpha \beta_{1}\left[\left(0-\bar{V}_{A V}\right)-\bar{V}_{C C}\right)\right] \\
\Delta V_{C C}=\alpha \beta_{D}\left(0-\bar{V}_{C C}\right)\end{array}$ \\
\hline
\end{tabular}

taken from Daly \& Daly, 1982). If the $\lambda$ value is less than $\overline{\mathrm{V}}_{\mathrm{AP}}$, as may happen during extinction training when $\lambda=0$, the change in $V_{A P}$ is negative and the approach gradient decreases (see Table 1, lower left equation). Up to this point, RWMOD and DMOD are identical. However, for DMOD, whenever the organism receives a smaller reward than expected ( $\lambda$ is less than $\bar{V}_{A P}$ ), the goal event is assumed to be aversive and an avoidance gradient is conditioned $\left(\mathrm{V}_{\mathrm{AV}}\right)$. The $\lambda$ value is the discrepancy between the strength of the learned expectancy for reward $\left(\overline{\mathrm{V}}_{\mathrm{AP}}\right)$ and what was obtained ( 0 on an extinction trial). Therefore, the $\lambda$ value to condition $\mathrm{V}_{\mathrm{AV}}$ is $0-\overline{\mathrm{V}}_{\mathrm{AP}}$. However, it is further assumed that an aversive event is more important to the organism than an appetitive event (see Kahneman \& Tversky, 1982), and therefore the $\lambda$ value used to condition $\mathrm{V}_{\mathrm{AV}}$ is twice the discrepancy: $2\left(0-\overline{\mathrm{V}}_{\mathrm{AP}}\right)$ (see Table 1, lower center equation). (Note: $V_{A V}$ is typically a negative number; the larger the $\mathrm{V}_{\mathrm{AV}}$ value, the more negative it is.) If the reward received is larger than expected ( $\lambda$ is larger than $\bar{V}_{A P}$ ), as may happen when a food reward is given after extinction training, no aversiveness is aroused and therefore the $\lambda$ value for conditioning $\mathrm{V}_{\mathrm{AV}}$ is zero and $\mathrm{V}_{\mathrm{AV}}$ declines (becomes less negative; see Table 1, upper center equation). Also, once an expectancy for aversiveness $\left(\mathrm{V}_{\mathrm{AV}}\right)$ is conditioned and the goal event is not aversive, courage to approach the aversive goal event is conditioned $\left(\mathrm{V}_{\mathrm{CC}}\right.$, i.e., counterconditioning, occurs). The $\lambda$ value is the discrepancy between the strength of the learned expectancy for aversiveness $\left(\overline{\mathrm{V}}_{\mathrm{AV}}\right)$ and the amount of aversiveness aroused ( 0 on a food-rewarded trial). Therefore, the $\lambda$ value to condition $V_{C C}$ is $0-\bar{V}_{A V}$ (see Table 1 , upper right equation). If courage is conditioned and an aversive goal event occurs (e.g., no food), the $\lambda$ value for conditioning $\mathrm{V}_{\mathrm{CC}}$ is zero and $\mathrm{V}_{\mathrm{CC}}$ declines (see Table 1, lower right equation).

The three $\mathrm{V}$ values both increase and decrease in magnitude. It is assumed that they increment at a higher rate than they decrement (see Rescorla \& Wagner, 1972). Thus, there are two $\beta$ values: $\beta_{\mathrm{I}}$ is used whenever a $V$ value increments in absolute value, and $\beta_{D}$ is used whenever a $\mathrm{V}$ value decrements in absolute value, and $\beta_{\mathrm{I}}>\beta_{\mathrm{D}}$.

Behavior of an organism is determined by the total $V$ value $\left(V_{T}\right)$, which is assumed to be the sum of the three $V$ gradients: $V_{T}=\bar{V}_{A P}+\bar{V}_{A V}+\bar{V}_{C C}$. It is further assumed that $\mathrm{V}_{\mathrm{AV}}$ has a steep spatial generalization gradient and has approximately one-half of its strength about $5 \mathrm{ft}$ from the goal event (the start-speed measure in a typical runway used for rats). Thus, to calculate start speed, $\mathrm{V}_{\mathrm{T}}=\overline{\mathrm{V}}_{\mathrm{AP}}+.5 \overline{\mathrm{V}}_{\mathrm{AV}}+\overline{\mathrm{V}}_{\mathrm{CC}}$, and to calculate run speeds (the speed of traversing the center portion of a runway), $\mathrm{V}_{\mathrm{T}}=\overline{\mathrm{V}}_{\mathrm{AP}}+.75 \overline{\mathrm{V}}_{\mathrm{AV}}+\overline{\mathrm{V}}_{\mathrm{CC}}$. However, $\mathrm{V}_{\mathrm{AV}}$ has to reach threshold (currently assumed to be .12) before it influences $V_{T}$. Therefore, nonreward in the presence of an expectancy for a small reward is not aversive.

It is generally agreed that a stimulus previously paired with a goal event such as food can serve as a reinforcer, and is called a conditioned or secondary reinforcer. The computer program includes an option that allows one to simulate predictions of DMOD if secondary reinforcers are present. The same linear operator equation is used to condition changes in $\mathrm{V}$ values, but the $\lambda$ value used is the $\mathrm{V}$ strength of the stimulus directly paired with the original goal event.

For further details concerning the assumptions and application of DMOD to behavioral phenomena, refer to Daly and Daly (1982).

\section{INSTRUCTION MANUAL}

To calculate predictions for appetitive leaming experiments using the simulation program, one must first make a number of decisions. These are required because the program is flexible, allowing one to enter many different values for parameters and types of trials to determine what effect certain assumptions have on predictions. For example, the program allows one to simulate multiphase experiments as well as those that involve both primary and secondary reinforcement.

The following instructions, together with three simulation examples, will help those unfamiliar with running computer simulations of mathematical models. The first example consists of 30 continuous reinforcement (CRF) acquisition trials (printed out in blocks of 5 trials), followed by 30 extinction trials (printed out for each individual trial), with one cue present on all trials. The second example is of partial reinforcement acquisition with 6 trials/block and reinforced and nonreinforced trials alternating $(+-+-+-)$. The third example is of a discrimination, and includes secondary reinforcement. Cue 1 is the stimulus present on all reinforced trials ( $\mathbf{S}+$ ). Cue 2 is the stimulus present on all nonreinforced trials (S-). Cue 3 is the stimulus common to $\mathrm{S}+$ and $\mathrm{S}-$ trials (e.g., background or context stimuli). Cue 4 is the stimulus receiving secondary reinforcement from Cues 1 
and 3 on one trial type, and Cues 2 and 3 on a second trial type. Only two blocks of 2 trials/block are given in acquisition, followed by 5 extinction trials with Cues 1 , 3 , and 4 present.

Before running a simulation, you must make the following decisions:

1. How many different types of trials are there?

2 . What cues are present on which trials?

3. What is the salience ( $\alpha$ level) for each cue (we use a value of 1 for all cues unless testing the effects of reduced salience)?

4. What is the size of the growth-rate parameter $\left(\beta_{\mathrm{I}}\right.$; this value is determined by drive level; we use a value of .15 for hungry organisms)?

5 . Is the growth-rate parameter the same for all three $V$ values, $V_{A P}, V_{A V}$, and $V_{C C}$ (it is currently assumed that $\beta_{\mathrm{I}}$ for $\mathrm{V}_{\mathrm{AV}}$ is lowered by certain drugs, but under all other conditions the $\beta_{I}$ values are the same for all three $\mathrm{V}$ values)?

6. What is the size of the decrement-rate parameter $\left(\beta_{D}\right.$; assumed to be .05 for all three $V$ values under all conditions)?

7. How many different reward magnitudes are used ( $\lambda$ level-1.0 is a very large reward, and 0 is used for nonrewarded trials and is entered as one of the $\lambda$ levels; only three $\lambda$ values are permitted in a simulation)?

8. Does the experiment involve secondary (conditioned) reinforcement? If not, enter 0 when the program asks for the number of secondary cues, and the experiment simulated will contain only primary reinforcement. If it does, first enter the number of secondary cues on that trial and then their actual numbers. A given cue can receive primary and secondary reinforcement in the same experiment, and even on the same trial.

The comments below are numbered to follow the numbers on the listings of the three simulation examples (see Appendix A). The first number refers to the example number. Underlined letters and numbers in the examples are those that you enter. All others are printed by the computer.

Comment \#

1.1 Call up the program. Each computer system is slightly different. The Digital Equipment Corporation PDP-11/34 uses OLD DMOD. The Northstar Horizon microcomputer uses LOAD "DMOD" after you have loaded the CP/M operating system and MICROSOFT BASIC (MBASIC).

1.2 Type RUN. A prompting message will ask you to enter values for beta $(\beta)$, alpha $(\alpha)$ for each cue, lambda $(\lambda)$, trial types, etc. You must enter numeric values for each question, and you must hit RETURN after each entry.

1.3 EQUAL BETAS, $\mathrm{Y}=\mathrm{YES}, \mathrm{N}=\mathrm{NO}$ ? If you want $\beta_{I}$ values for each equation to be one value and $\beta_{D}$ values for each equation to be another value, enter $\mathrm{Y}$, and then on the next line enter values such as .15 for INC BETA $\left(\beta_{\mathrm{I}}\right)$ and .05 for DEC BETA $\left(\beta_{\mathrm{D}}\right)$. If you want different $\beta$ values for each equation (e.g., alcohol is assumed to reduce $\beta_{\mathrm{I}}$ for $\mathrm{V}_{\mathrm{AV}}$ only), enter $\mathrm{N}$, and enter three values, one for $V_{A P}$, one for $V_{A V}$, and one for $\mathrm{V}_{\mathrm{CC}}$ (see Example Comment 2.1).

1.4 \# OF CUES? Put in one number indicating the total number of different cues in the simulation. The total number includes all primary and secondary cues; therefore, primary and secondary cues are not numbered separately (that is, Cues 1-3 may be primary cues and Cue 4 a secondary cue).

1.5 ALPHAS FOR CUES 1 to . Put in one number per line for each cue, e.g., ?1, ?.2, ?1, or ?1. In this example, Cue 2 has an alpha equal to .2; Cues 1,3 , and 4 all have alphas of 1 (see Example 3).

1.6 NUMBER OF LAMBDA LEVELS $(1,2,3)$ ? You may enter 1,2 , or 3 . These are the $\lambda$ values for $V_{A P}$, that is, size of the food reward.

LAMBDA FOR LEVEL 1. Enter the lambda level desired. The maximum value we run is 1.0 .

LAMBDA FOR LEVEL 2. A value of 0 for extinction is considered a lambda value, and must be entered as a separate lambda level.

1.7 TRIAL TYPES. If you have only one type of trial (e.g., all trials are reinforced on a CRF schedule), enter 1 . If you are running a partial reinforcement schedule, enter 2 (one will be the reinforced trial, and the other, the nonreinforced trial). However, the program calculates the mean $\mathrm{V}$ value across all trial types. If you wish to obtain the mean for a larger block of trials, put in as many trial types as you want in the block. For example, if you want three reinforced and three nonreinforced trials in alternating sequence $(+-+-+-)$ in each block of six trials, enter 6 (see Example 2).

1.8 REPETITIONS OF TRIAL TYPE 1 . If you want five CRF trials, enter 5, and if just one trial, enter 1 .

1.9 NUMBER OF PRIMARY CUES. Enter the total number of cues that should receive primary reinforcement on this trial.

1.10 INPUT EACH PRIMARY CUE. Enter the number of each cue (one per line) that should receive primary reinforcement on this trial (see Example Comment 3.1 for an example with two cues).

1.11 NUMBER OF SECONDARY CUES. Enter the total number of cues that should receive secondary reinforcement. If you wish to run only primary reinforcement, enter 0. (See Example Comment 3.2 for an example in which secondary reinforcement is used.) The same cue may receive both primary and secondary reinforcement on the same trial.

3.3 INPUT EACH SECONDARY CUE. Enter the number of each cue (one per line) that should receive secondary reinforcement.

3.4 NUMBER OF REINFORCING CUES. Enter the total number of reinforcing cues, that is, those cues that provide secondary reinforcement. The values of $\mathrm{V}$ of these reinforcing cues will be entered as the $\lambda$ level in the learning equation. The reinforcing cues are typically those entered as primary cues on that trial (see Example 3). 
3.5 INPUT EACH REINFORCING CUE. Enter the number of each cue (one per line) that should provide secondary reinforcement.

1.12 LAMBDA LEVEL 1, 2, or 3. Enter 1,2, or 3 to indicate which lambda level for $V_{A P}$ (primary reinforcement) you want for that trial.

If you have entered more than one trial type, you will be prompted with the same questions again for the other trial types (see Example Comment 2.2).

1.13 RESPONSE MEASURE CONSTANT. The program automatically calculates $\mathrm{V}$ for start, run, and goal measures; that is, it multiplies $\mathrm{V}_{\mathrm{AV}}$ by $.5, .75$, and 1.0 , since it is assumed that, the further you are spatially away from the goal, the less $V_{T}$ influences behavior. The program also allows you to select a different constant to multiply times $\mathrm{V}_{\mathrm{AV}}$ in order to calculate $\mathrm{V}_{\mathrm{T}}$ (called the response measure constant). For example, we use a response measure constant of .9 to predict choice behavior approximately $2 \mathrm{ft}$ from the goal area. When calculating $V_{T}$, the program does not automatically eliminate $\mathrm{V}_{\mathrm{AV}}$ if its value is below threshold. If you want to eliminate $V_{A V}$ in the $V_{T}$ calculation, type 0 for the response measure constant. You may want to use this option, as we have, if a low $\lambda$ value is used or if a drug that influences the $\beta_{I}$ value for conditioning $V_{A V}$ has been given to the organism and the $V_{A V}$ value is below the assumed threshold.

1.14 \# OF BLOCKS? This causes the program to repeat calculations for all of the trial types entered for the specified number of times. For example, if six trial types were used $(+-+-+-)$, and you want to calculate $V$ values for a total of 30 trials, then enter 5 , and the program will repeat calculations for the 6 trials five times, for a total of 30 trials.

1.15 ENTER 1 FOR BLOCK MEANS ONLY, ELSE 0 . If you type 0 , the program will print the $V$ values for each cue on each trial individually and the mean $\mathrm{V}$ values across all trial types within a block. If you type 1 , it will print out only the mean $\mathrm{V}$ values for each block.

$1.16 \mathrm{~V}$ VALUES ON SCREEN $=1$, PRINTER $=2$, FILE $=3$. You have the option of seeing the calculated V values on the screen (enter 1), having them printed by a printer (enter 2), or placing them in a file (enter 3; usually used if you want to plot the results at a later time using the plot program $\left.{ }^{1}\right)$.

$1.17 \mathrm{~V}(\mathrm{AP}) \mathrm{V}(\mathrm{AV}) \mathrm{V}(\mathrm{CC}) \mathrm{AP}+\mathrm{AV}^{*} .5+\mathrm{CC} \mathrm{AP}+\mathrm{AV}^{*}$ $.75+C \mathrm{AP}+\mathrm{AV}+\mathrm{CC} \mathrm{AP}+\mathrm{AV} \mathrm{X}^{*}+\mathrm{CC}$. These are the headings for the columns of $\mathrm{V}$ values that are printed out. The program prints the $\mathrm{V}_{\mathrm{AP}}, \mathrm{V}_{\mathrm{AV}}, \mathrm{V}_{\mathrm{CC}}$ values for each cue separately, as well as the start, run, and goal measure value of $V_{T}$, and the $V_{T}$ value including the response measure constant you entered, in that order.

\section{Hints for Understanding Printout}

Cue order on printout. If there is more than one cue, the $V$ values for Cue 1 appear in the first row, Cue 2 in the second row, Cue 3 in the third row, etc. Cue numbers are not labeled on the printout (see Example 3).

Keep records. It is important to keep records of what cue number goes with which cue; for example, Cue $1=$ St, Cue $2=\mathrm{S}-$, Cue $3=$ common cue (see Example 3 ). We usually write these on the first page of the printout, together with the name of the phenomenon simulated.

Outline simulation. Before you begin to run a simulation, it is wise to decide exactly what parameter values you will use, and what cues will be present on each trial type. We usually write them down and then compare the values with those printed out at the beginning of each simulation printout.

Rescorla-Wagner model. The values of the first column, called $V_{A P}$, are identical to the predictions of the Rescorla-Wagner model.

1.18 1=MORE CALC, 2=DIFFERENT OUTPUT, $3=$ RESET PARAMETERS, 4=END.

MORE CALC: If you wish to run additional trials of the same simulation, enter 1 . For example, if you had run 12 blocks of trials but asymptote was not reached, and you wish to continue for another 12 blocks, you would use the MORE CALC option (see Example Comment 2.3).

DIFFERENT OUTPUT: If you wish to change from any device (screen, printer, file) to any other, enter 2 . For example, if you had run the simulation using the screen option and now want to run the simulation again but to obtain a printed copy, you would enter 2 . This option may not be used if you have previously used the RESET PARAMETERS option (see below).

RESET PARAMETERS: If the experiment you wish to simulate has two or more phases in it, you will want to enter the trial types for the new phase after the first phase has been simulated. If you enter 3 , the program will not erase the $V$ values of the cues at the end of the first phase. You will be given a choice. You may reenter all the parameter values and trial types (enter 1; see Example Comment 1.19), or you may keep the same $\alpha, \beta$, and $\lambda$ values but enter only new trial types (enter 2 , see Example Comment 3.6). For example, different cues may be present on different trials in the second phase of an experiment, or the same cues may be present but the reward magnitude has been changed on a given trial. Use the RESET PARAMETERS option only for different phases of an experiment for the same group of subjects. If you want to simulate a different group in the same experiment, you must enter 4 (for the END option), and then type RUN to start the program again (i.e., all $\mathrm{V}$ values must begin at 0 for a new group).

END: Enter 4 if you have completed the simulation of this group. You may then enter RUN to start the program again and begin the simulation of another group (the $\mathrm{V}$ values of the completed simulation will be erased).

Running the three simulation examples exactly as we have done should indicate whether or not there are any problems in your copy of the program. If you do not obtain the same $\mathrm{V}$ values, check every line entered. If you still cannot obtain the same results, please let us know. Repeating these simulations should also help those not familiar with simulation techniques to learn 
to simulate other types of experiments. The most important task when simulating is to make a complete list of all the stimuli present on each type of trial. Failure to accurately analyze the experimental procedure will surely result in inaccurate predictions.

\section{REFERENCES}

Amse L, A. (1958). The role of frustrative nonreward in continuous reward situations. Psychological Bulletin, 55, 102-119.

Bush, R. R., \& Mostellen, F. (1955). Stochastic models for learning. New York: Wiley.

DALY, H. B. (1974). Reinforcing properties of escape from frustration aroused in various learning situations. In G. H. Bower (Ed.), The psychology of learning and motivation (Vol. 8). New York: Academic Press.

DALY, H. B., \& DALY, J. T. (1982). A mathematical model of re- ward and aversive nonreward: Its application in over $\mathbf{3 0}$ appetitive learning situations. Journal of Experimental Psychology: General, 111, 441-480.

Kahneman, D., \& Tvensky, A. (1982). The psychology of preferences. Scientific American, 246(1), 160-173.

Rescorla, R. A., \& Wagner, A. R. (1972). A theory of Pavlovian conditioning: Variations in the effectiveness of reinforcement and nonreinforcement. In A. H. Black \& W. F. Prokasy (Eds.), Classical conditioning II: Current research and theory. New York: Appleton-Century-Crofts.

\section{NOTE}

1. A separate program that plots the results for any desired combination of cues, uses manual or automatic scaling, labels axes, etc., is available from the authors. The program is written in MICROSOFT BASIC for a HiPlot plotter, and uses DMODproduced data as stored by the file subroutine.

\section{Example 1: CRF Acquisition and Extinction}

Comment \#

$\begin{array}{ll}1.1 & \text { LOAD "DMOD" } \\ 1.2 & \underline{\text { RUN }}\end{array}$

DMOD SIMULATION PROGRAM

1.3 EQUAL BETAS? , Y=YES, N=NO- $>$ ? $\underline{Y}$

INC BETA .15

DEC BETA $\overline{.05}$

1.4 \# OF CUES ?

? 1

I.5 AL 5 PHAS FOR CUES 1 TO 1

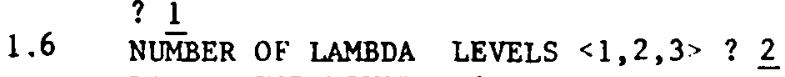
LAMBDA FOR LEVEL 1

? 1

LAMBDA FOR LEVEL 2

? 0

1.7 TR TAL TYPES

1.8 ? 1

1.8 REPETITIONS OF TRIAL TYPE 1

? 5

1.9 NÜMBER OF PRIMARY CUES ? 1

1.10 INPUT EACH PRIMARY CUE

? 1

1.11 NUMMBER OF SECONDARY CUES ? 0

1.12 LAMBDA LEVEL 1 OR 2 ?

? 1

1.13 RESPONSE MEASURE CONSTANT ? .9

1.14 \# OF BLOCKS

? 6

1.15 ENTER 1 FOR BLOCK MEANS ONLY, ELSE 01

$1.16 \mathrm{~V}$ VALULS ON SCREEN $=1$, PRINTER $=2$, FILE $=31$

$1.17 \mathrm{~V}(\mathrm{AP}) \mathrm{V}(\mathrm{AV}) \mathrm{V}(\mathrm{CC}) \mathrm{AP}+\mathrm{AV} * .5+\mathrm{CC} A \mathrm{AP}+\mathrm{AV} * .75+\mathrm{CC} A \mathrm{AP}+\mathrm{AV}+\mathrm{CC} \quad \mathrm{AP}+\mathrm{AV} * .9+\mathrm{CC}$

BLOCK MEANS

$\begin{array}{lllllll}0.3695 & 0.0000 & 0.0000 & 0.3695 & 0.3695 & 0.3695 & 0.3695 \\ \vdots & & & & & & \end{array}$


Comment \#

BLOCK MEANS

0.9892

0.0000

0.0000

0.9892

0.9892

0.9892

0.9892

$1.181=$ MORE CALC , 2=DIFFERENT OUTPUT , $3=$ RESET PARAMETERS , $4=$ END $\underline{3}$

$1.191=$ RE-ENTER ALL VALUES, $2=$ RE-ENTER TRIAL TYPES 1

EQUAL BETAS?, $\mathrm{Y}=\mathrm{YES}, \mathrm{N}=\mathrm{NO}-\rightarrow>$ ? $\underline{\mathrm{Y}}$

INC BETA .15

DEC BETA $\overline{.05}$

\# OF CUES ?

? 1

ALPHAS FOR CUES 1 TO 1

? 1

NUMBER OF LAMBDA LEVELS $\langle 1,2,3\rangle ? \underline{2}$

LAMBDA FOR LEVEL 1

? 1

LAMBDA FOR LEVEL 2

? 0

TRIAL TYPES

? 1

REPETITIONS OF TRLAL TYPE 1

$? 30$

NUMBER OF PRIMARY CUES ? 1

INPUT EACH PRIMARY CUE

? 1

NÜMBER OF SECONDARY CUES ?

LAMBDA LEVEL 1 OR 2 ?

? 2

RESPPONSE MEASURE CONSTANT? $\stackrel{9}{9}$

\# OF BLOCKS

? 1

ENTER 1 FOR BLOCK MEANS ONLY, ELSE 0 O

$\checkmark$ VALUES ON SCREEN $=1$, $P R I N T E R=2$, FILE $=31$

$V(A P) \quad V(A V) \quad V(C C) \quad A P+A V * .5+C C A P+A V * .75+C C A P+A V+C C A P+A V * .9+C C$

$\begin{array}{lllllll}0.9428 & -0.2977 & 0.0000 & 0.7939 & 0.7195 & 0.6450 & 0.6748 \\ 0.8956 & -0.5359 & 0.0000 & 0.6277 & 0.4937 & 0.3597 & 0.4133\end{array}$

$\begin{array}{lllllll}0.2242 & -0.8999 & 0.0000 & -0.2257 & -0.4507 & -0.6757 & -0.5857 \\ 0.2130 & -0.8773 & 0.0000 & -0.2257 & -0.4450 & -0.6643 & -0.5766\end{array}$

BLOCK MEANS

$\begin{array}{lllllll}0.4936 & -1.0153 & 0.0000 & -0.0140 & -0.2678 & -0.5217 & -0.4201\end{array}$

If you had decided to obtain hardcopy and had typed 2 when asked,

$V$ values on screen=1, print $=2, f i l e=3$, the following printout would have

been given. Note that all the values entered are summarized in table form (only the CRF phase is presented here).

DMOD SIMULATION

INC. BETA $=.15$

NUMBER OF CUES 1

DEC. BETA $=.05$

LAMBDAS: 10

ALPHAS : 1 
TRIAL

1

AP

AV

5
CUES PRESENT

PRIM 1

SEC

REINF
LAMBDA LEVEL

1

$\begin{array}{lllllll}\text { AP } & \text { AV } & \text { CC } & \operatorname{VT}(.5 \mathrm{AV}) & \operatorname{VT}(.75 \mathrm{AV}) & \mathrm{VT} & \operatorname{VT}(.9 \mathrm{AV}) \\ \begin{array}{l}\text { BLOCK MEANS } \\ 0.3695 \quad 0.0000\end{array} & 0.0000 & 0.3695 & 0.3695 & 0.3695 & 0.3695\end{array}$

Comment \#

Example 2: Partial Reinforcement Acquisition

$\underline{\text { RUN }}$

DMOD SIMULATION PROGRAM

2.1 EQUAL BETAS? $, \mathrm{Y}=\mathrm{YES}, \mathrm{N}=\mathrm{NO}-\rightarrow>$ ? N

INPUT 3 BETA VALUES FOR $V(A P), V(A V), V(C C)$

PRIMARY INC. BETAS $\rightarrow ?+15, .15, .15$

PRIMARY DEC. BETAS $\rightarrow$ ? $\frac{.05, .05, .05}{.05,015,15}$

SECONDARY INC.BETAS $\rightarrow$ ? $15, .15, .15$

SECONDARY DEC. BETAS $\rightarrow$ ? $\frac{.05, .05, .05}{105}$

\# OF CUES ?

? 1

ALPHAS FOR CUES 1 TO 1

? 1

NUMBER OF LAMBDA LEVELS $\langle 1,2,3\rangle ? 2$

LAMBDA FOR LEVEL 1

$? \underline{1}$

LAMBDA FOR LEVEL 2

? 0

TRIAL TYPES

? 6

REPETITIONS OF TRIAL TYPE 1

? 1

NUMBER OF PRIMARY CUES ? 1

INPUT EACH PRIMARY CUE

$? \underline{1}$

NUMBER OF SECONDARY CUES ? $\underline{0}$

LAMBDA LEVEL 1 OR 2 ?

? 1

2.2 REPETITIONS OF TRIAL TYPE 2

? 1

NUMBER OF PRIMARY CUES ? 1

INPUT EACH PRIMARY CUE

$? \underline{1}$

NUMBER OF SECONDARY CUES ? 0

If you want unequal $\beta$ values

type $N$, and then enter $B_{I}$ and

$B_{D}$ values for calculating

$v_{A P}, v_{A V}$, and $v_{C C}$ values for

primary and secondary reinforce-

ment separately. In this example

the same values were entered.

However, if one were simulating

a drug experiment (e.g., alcohol)

and one assumes that alcohol

decreases the growth rate

parameter $\left(\beta_{I}\right)$ to .07 for condi-

tioning $v_{A V}$ only, then one would

enter the following, values:

$? .15, .07, .15$

$? .05, .05, .05$

$? .15, .07, .15$

$? .05, .05, .05$

$? \underline{2}$

REPETITIONS OF TRIAL TYPE 3

$? \underline{1}$

NUMBER OF PRIMARY CUES ? 1

INPUT EACH PRIMARY CUE

$? 1$

NUMBER OF SECONDARY CUES ? $\underline{0}$

LAMBDA LEVEL 1 OR 2 ?

$? \underline{1}$

REPETITIONS OF TRIAL TYPE 4

? 1 
Comment \#

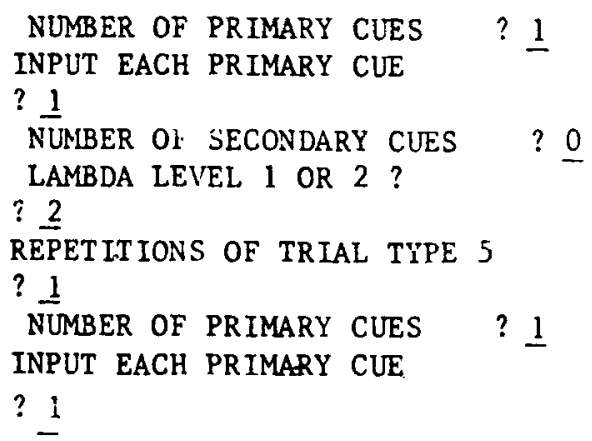

2.3 1=MORE CALC, 2=DIFFERENT OUTPUT, 3=RESET PARAMETERS, 4=END 1

BLOCK MEANS
0.7595
$-1.1808$
0.9109
1.0801
0.7849
0.4897
0.6078
BLOCK MEANS
0.7597
$-1.1840$
0.9226
1.0903
0.7943
0.4983
0.6167

1=MORE CALC, 2=DJFFERENT OUTPUT, 3=RESET PARAMETERS, 4=END 4

Example 3: Discrimination Learning

RUN

DMOD SIMULATION PROGRAM

EQUAL BETAS?, Y=YES, N=NO-->? $\underline{Y}$ 


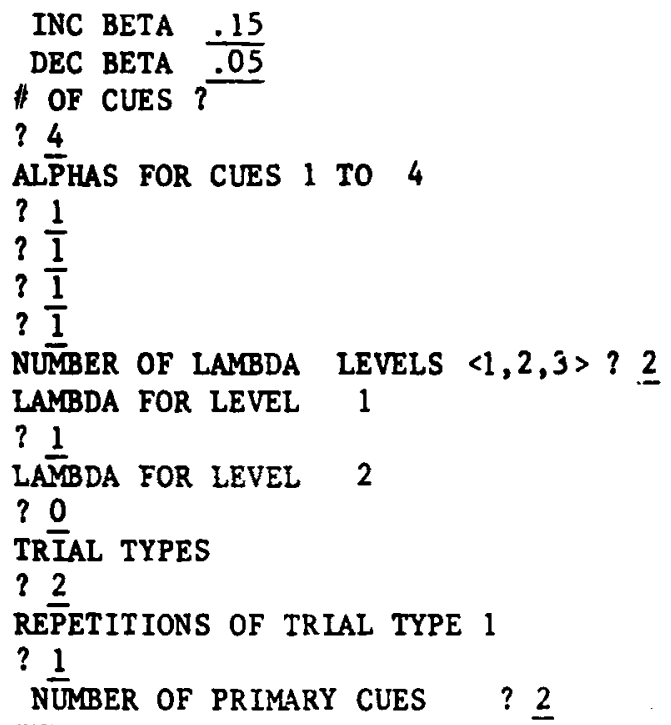

$? \frac{2}{3}$

$? \overline{3}$

LAMBDA LEVEL 1 OR 2 ?

? 2

RËSPONSE MEASURE CONSTANT? 9 \# OF BLOCKS

$? 2$.

ENTTER 1 FOR BLOCK MEANS ONLY, ELSE 00 $\checkmark$ VALUES ON SCREEN=1, PRINTER=2, FILE=3 1

$V(A P) \quad V(A V) \quad V(C C) \quad A P+A V * .5+C C A P+A V * .75+C C A P+A V+C C A P+A V * .9+C C$
0.1500
0.0000
0.0000
0.1500
0.1500
0.1500
0.1500
0.0000
0.0000
0.0000
0.0000
0.0000
0.1500
0.0000
0.0000
0.1500
0.1500
0.1500
0.1500
0.0000
0.0000
0.0000
0.0000
0.0000
0.0000 
Comment \#

$\begin{array}{rrrrrrr}0.1500 & 0.0000 & 0.0000 & 0.1500 & 0.1500 & 0.1500 & 0.1500 \\ -0.0075 & -0.0450 & 0.0000 & -0.0300 & -0.0413 & -0.0525 & -0.0480 \\ 0.1425 & -0.0450 & 0.0000 & 0.1200 & 0.1088 & 0.0975 & 0.1020 \\ 0.0225 & 0.0000 & 0.0000 & 0.0225 & 0.0225 & 0.0225 & 0.0225 \\ & & & & & & \\ \text { BLOCK MEANS } & & & & & & \\ 0.1500 & 0.0000 & 0.0000 & 0.1500 & 0.1500 & 0.1500 & 0.1500 \\ -0.0075 & -0.0450 & 0.0000 & -0.0300 & -0.0413 & -0.0525 & -0.0480 \\ 0.1463 & -0.0225 & 0.0000 & 0.1350 & 0.1294 & 0.1238 & 0.1260 \\ 0.0113 & 0.0000 & 0.0000 & 0.0113 & 0.0113 & 0.0113 & 0.0113 \\ & & & & & & \\ 0.2561 & 0.0023 & 0.0068 & 0.2640 & 0.2646 & 0.2651 & 0.2649 \\ -0.0075 & -0.0450 & 0.0000 & -0.0300 & -0.0413 & -0.0525 & -0.0480 \\ 0.2486 & -0.0428 & 0.0068 & 0.2340 & 0.2233 & 0.2126 & 0.2169 \\ 0.0630 & -0.0068 & 0.0000 & 0.0596 & 0.0579 & 0.0563 & 0.0569 \\ & & & & & & \\ 0.2561 & 0.0023 & 0.0068 & 0.2640 & 0.2646 & 0.2651 & 0.2649 \\ -0.0196 & -0.1042 & -0.0003 & -0.0720 & -0.0980 & -0.1241 & -0.1137 \\ 0.2366 & -0.1019 & 0.0064 & 0.1920 & 0.1665 & 0.1411 & 0.1512 \\ 0.0897 & -0.0189 & 0.0010 & 0.0813 & 0.0766 & 0.0718 & 0.0737 \\ & & & & & & \\ \text { BLOCK MEANS } & & & & & & \\ 0.2561 & 0.0023 & 0.0068 & 0.2640 & 0.2646 & 0.2651 & 0.2649 \\ -0.0196 & -0.1042 & -0.0003 & -0.0720 & -0.0980 & -0.1241 & -0.1137 \\ 0.2426 & -0.0723 & 0.0066 & 0.2130 & 0.1949 & 0.1768 & 0.1841 \\ 0.0764 & -0.0128 & 0.0005 & 0.0705 & 0.0672 & 0.0640 & 0.0653\end{array}$

3.6 1=MORE CALC, 2=DIFFERENT OUTPUT, 3=RESET PARAMETERS, 4=END $\underline{3}$

1=RE-ENTER ALL VALUES, 2=RE-ENTER TRIAL TYPES $\underline{2}$

TRIAL TYPES

$\underline{1}$

REPETITIONS OF TRIAL TYPE 1

? 5

NUMUER OF PRIMARY CUES ? 2

INPUT EACH PRIMARY CUE

$? \frac{1}{3}$

NUMBBER OF SECONDARY CUES, ? 1 INPUT EACH SECONDARY CUE

? 4

NUTMER OF REINFORCING CUES ? 2

INPUT EACH REINFORCING CUE

$? \frac{1}{3}$

$? \frac{1}{3}$

LAMBDA LEVEL 1 OR 2 ?

? 2

RETSPONSE MEASURE CONSTANT? .9

\# OF BLOCKS

? 1

ENTER 1 FOR BLOCK MEANS ONLY, ELSE 00

$\checkmark$ VALUES ON SCREEN=1, PRINTER=2, FILE=3 1

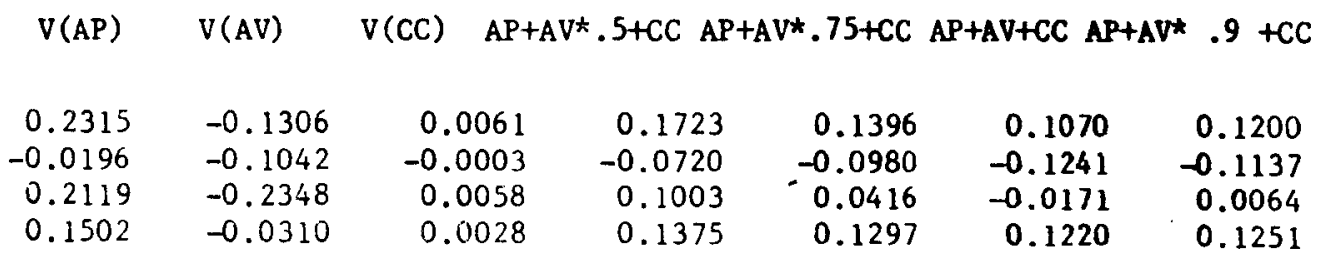




$\begin{array}{rrrrrrr}0.1552 & -0.2685 & 0.0041 & 0.0251 & -0.0421 & -0.1092 & -0.0823 \\ -0.0196 & -0.1042 & -0.0003 & -0.0720 & -0.0980 & -0.1241 & -0.1137 \\ 0.1357 & -0.3726 & 0.0037 & -0.0469 & -0.1401 & -0.2332 & -0.1960 \\ 0.2568 & -0.2793 & 0.0062 & 0.1233 & 0.0535 & -0.0163 & 0.0116\end{array}$

\begin{tabular}{|c|c|c|c|c|c|c|}
\hline BLOCK & IEANS & & & & & \\
\hline 0.1914 & -0.2251 & 0.0050 & 0.0838 & 0.0276 & -0.0287 & -0.0062 \\
\hline CUE 2 & NOT PRESENT & & & & & \\
\hline 0.1718 & -0.3293 & 0.0047 & 0.0119 & -0.0705 & -0.1528 & -0.1199 \\
\hline 0.2142 & -0.1509 & 0.0048 & 0.1436 & 0.1059 & 0.0681 & 0.0832 \\
\hline
\end{tabular}

1=MORE CALC, 2=DIFFERENT OUTPUT , 3=RESET PARAMETERS, 4=END $\underline{4}$

Printout of Example 3 if printer option had been selected DMOD SIMULATION

INC. BETA $=.15$ NUMBER OF CUES 4 LAMBDAS: 10

TRIAL REP/TRIAL

1

2

AP

0.1500

0.0000

0.1500

0.0000
1

1

DEC. $B E T A=.05$

ALPHAS: 1111

CUES PRESENT

PRIM 13

$\begin{array}{lll}\text { SEC } & 4 & \\ \text { REINF } & 1 & 3\end{array}$

PRIM 23

SEC 4

REINF 23
LAMBDA LEVEL

1

2

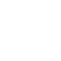

(n)


180 REM RL 1 (T)

190 REM BETAS

200 REM PRIM-I

210 REM $-D$

220 REM SEC - I

230 REM $-D$

240 REM T2\%

250 REM T1\%

260 REM R\%(I)

270 REM RIX(I)

2BO REM B1X

290 REM IEO

300 REM IPL

310 REM C(TRIAL TYPE, CUE)

320 REM D1*

330 REM F1\$

340 REM A1\$

350 REM

\#\#"

370 REM DIM SET FOR MAX OF 20 CUES

380 DIM B1 (3), B2(3), Z1 (3), Z2(3), Z3(3), P (20), RL1 (5)

$390 \mathrm{DIM} A 1(20), A 2(20), A 3(20), C(20,20), R 1 \times(20), R \times(20)$

400 DIM Ce (20), C3(20), C4 (20), M1 (20), Me (20), M3(20), N(20)

410 REM

420 REM

430 REM

440 REM

450 PRINT "

****

\section{INPUT ROUTINE}

DMOD SIMLLATION PROGRAM

" PRINT

460 INPUT "EQUAL BETAS?, Y=YES, N=NO--)";A1

470 IF $A 1 \$=" Y "$ OR A1\$="Y" THEN GOTO 1740: REM RUICK INPUT ROUTINE

480 PRINT "INPUT 3 BETA VALUES FOR V(AP), V(AV), V(CC)"

490 INPUT "PRIMARY INC. BETAS - $)$ "B1(1), Be(1),B3(1)

500 INPUT "PRIMARY DEC. BETAS - ) " $\mathrm{B} 1(2), \mathrm{BE}(2), \mathrm{B} 3(2)$

510 INPUT "SECONDARY INC. BETAS - $) " ; B 4(1), B 5(1), B 6(1)$

$5 E 0$ INPUT "SECONDARY DEC. BETAS - ) ", B4(2), B5(2), B6(2)

530 PRINT "* OF CUES ? " \& INPUT C1

540 PRINT "ALPHAS FOR CUES 1 TO " $\mathrm{C1}$

550 FOR I=1 TO C1:INPUT P(I):NEXT I

560 INPUT "NUMBER DF LAMBDA LEVELS $(1,2,3)$ " T2X

570 FOR L=1 TO T2X,PRINT "LAMBDA FOR LEVEL "'LIINPUT RLI(L) INEXT L

580 PRINT "TRIAL TYPES "INPUT T1*

590 REM **** INPUT FOR BLDCK ****

600 FOR $I=1$ TO $T 1 X$

610 PRINT "REPETITIONS OF TRIAL TYPE",I:INPUT RX(I)

620 INPUT " NUMBER OF PRIMARY CUEB

630 PRINT "INPUT EACH PRIMARY CUE

640 FOR $J=1$ TO $C 2$ : INPUT $C(I, J)$ \&NEXT $J$

650 INPUT " NLMBER OF SECONDARY CUES ",C3(I), C3EC3(I)

660 IF $C 3=0$ THEN $C 4=0: C 4(1)=0:$ :

670 PRINT "INPUT EACH SECONDARY CUE "

680 FQR $J=C 2+1$ TO $C 2+C 3$ : INPUT $C(I, J)$, NEXT $J$

690 INPUT " NUMBER OF REINFORCING CUES ",C4(I) :C4=C4(I)

700 PRINT "INPUT EACH REINFQRCING CUE "

710 FOR $J=C 2+C 3+1$ TO $C 2+C 3+C 4:$ INPUT $C(I, J)$ : NEXT $J$

720 IF T2X=1 THEN PRINT "LAMBDA LEVEL 1 SELECTED " $R 1 \times(I)=1$, GOTO 760

730 IF TeX=2 THEN PRINT " LAMBDA LEVEL 1 OR 2 ?"

740 IF T2X=3 THEN PRINT " LAMBDA LEVEL 1,2 QR 3 ?"

750 INPUT $R 1 \times(I)$

760 NEXT I

770 INPUT " RESPQNSE MEASURE CONSTANT " $X$

789 PRINT "* OF BLOCKE" : INPUT B1\%

790 INPUT " ENTER 1 FOR BLOCK MEANS ONLY, ELSE Q ", IEO

BQ0 INPUT "V VALUES ON SCREEN=1, PRINTER=2, FILE=3 ", IPL

810 IF IPL=2 THEN GOSUB 2150 : REM OUTPUT HEADER TO PRINTER

B20 IF IPL $=3$ THEN GOSUB 1790: REM FILE HEADER INFO

830 REM HEADER 


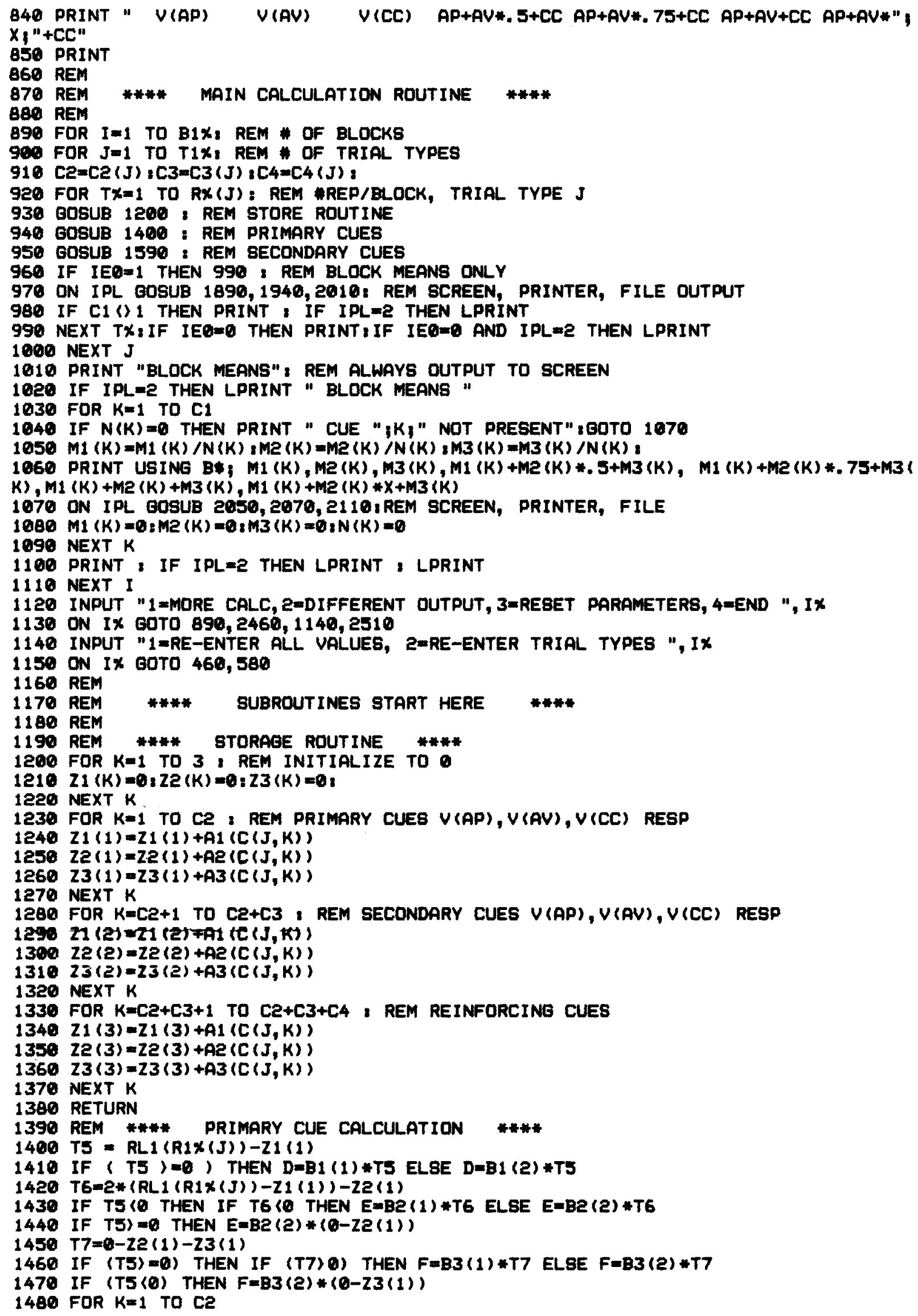


$1490 A 1(C(J, K))=A 1(C(J, K))+P(C(J, K)) * D$

$1500 M_{1}(C(J, K))=M 1(C(J, K))+A 1(C(J, K))$

$1510 A 2(C(J, K))=A C(C(J, K))+P(C(J, K)) * E$

$1520 \operatorname{ME}(C(J, K))=M 2(C(J, K))+A E(C(J, K))$

$1530 A 3(C(J, K))=A 3(C(J, K))+P(C(J, K)) * F$

$1540 M 3(C(J, K))=M 3(C(J, K))+A 3(C(J, K))$

$1550 N(C(J, K))=N(C(J, K))+1$

1560 NEXT K

1570 RETURN

1580 REM **** SEC CUE CALCLLATION ****

1590 IF $(Z 1(3)-Z 1(2))=0)$ THEN B4=B4(1) ELSE $B 4=B 4(2)$

1600 IF $(22(3)-Z 2(2)(=0)$ THEN BS=BS(1) ELSE BS=B5(2)

1610 If $(23(3)-23(2)\}=0)$ THEN B6=B6(1) ELSE B6=B6(2)

1620 FOR $\mathrm{K}=\mathrm{C} 2+1$ TO $\mathrm{C} 2+\mathrm{C} 3$

$1630 A 1(C(J, K))=A 1(C(J, K))+P(C(J, K)) * B 4 *(Z 1(3)-Z 1(2))$

$1640 M 1(C(J, K))=M 1(C(J, K))+A 1(C(J, K))$

$1650 A 2(C(J, K))=A 2(C(J, K))+P(C(J, K)) * B 5 *(Z 2(3)-Z 2(2))$

$1660 \operatorname{ME}(C(J, K))=M 2(C(J, K))+A Q(C(J, K))$

$1670 A 3(C(J, K))=A 3(C(J, K))+P(C(J, K)) * B 6 *(23(3)-23(2))$

$1680 M 3(C(J, K))=M 3(C(J, K))+A 3(C(J, K))$

$1690 N(C(J, K))=N(C(J, K))+1$

1700 NEXT K

1710 RETURN

1720 REM

1730 REM **** QUICK INPUT ROUTINE ****

1740 INPUT " INC BETA ", BI(1)

1750 INPUT " DEC BETA ",BI(2)

$1760 \mathrm{B2}(1)=\mathrm{B} 1(1), \mathrm{B} 3(1)=\mathrm{B} 1(1), \mathrm{B} 4(1)=\mathrm{B} 1(1), \mathrm{BS}(1)=\mathrm{B} 1(1), \mathrm{B} 6(1)=\mathrm{B} 1(1)$

$1770 \mathrm{~B} 2(2)=B 1(2), B 3(2)=B 1(2), B 4(2)=B 1(2), B 5(2)=B 1(2), B 6(2)=B 1(2)$

1780 BOTO 530

1790 REM *** BET UP HEADER FOR PLOT DATA FILE ****

1800 INPUT " DRIVE ? ", DI*

1810 INPUT " FILENAME. EXT ? ",F1*

1820 OPEN "O", \#1, D1*+", "+F1*

1830 PRINT *1,F1\$,", ", C1, ", ", B1X, ", ", T1X, ", ", IEO

1840 FOR KS=1 TO T1X : PRINT 1, RX (KS) : NEXT KS

1850 RETURN

1860 REM

1870 REM ***** BCREEN, PRINTER * PLOTTER OUTPUT ROUTINES

1880 REM ** GCREEN OUTPUT ***

1890 FOR $K=1$ TO C1 IREM ORDER OF CUES IS PRIMARY, SECONDARY AS ENTERED

1900 PRINT USING B*; $A 1(K), A 2(K), A 3(K), A 1(K)+A 2(K) * .5+A 3(K), A 1(K)+A 2(K) * .75+A 3(K$ ), $A 1(K)+A 2(K)+A 3(K), A 1(K)+A 2(K) * X+A 3(K)$

1910 NEXT K

1920 RETURN

1930 REM $K=1$ TO $C_{1}$

1950 LPRINT USING B*, AI (K), A2 (K), $A 3(K), A 1(K)+A 2(K) * 5+A 3(K), A 1(K)+A 2(K) * .73+A 3(K$ ), $A 1(K)+A 2(K)+A 3(K), A 1(K)+A 2(K) * X+A 3(K)$

1960 NEXT K

1970 RETURN

1980 REM

1990 REM

2000 REM

2010 IF IEQ=1 THEN EQSO, REM BLOCK MEANB FOR EACH CUE

2020 FOR $K=1$ TO $C 1$

2030 PRINT "1, A1 (K); ", ", A2 (K), ", " , A3 (K)

2040 NEXT $K$

2050 RETURN

2060 REM **** PRINTER BLOCK MEANS ****

2070 IF $N(K)=0$ THEN LPRINT "CUE " KK" NOT PRESENT" IRETURN

2080 LPRINT USING $B * 3, M 1(K), M 2(K), M 3(K), M 1(K)+M 2(K) * .5+M 3(K), M 1(K)+M 2(K) * .75+M 31$ $K), M 1(K)+M 2(K)+M 3(K), M 1(K)+M 2(K) * X+M 3(K)$

2090 RETURN

2100 REM **** FILE BLOCK MEANS ****

2110 IF IEO=0 THEN 2130 :

2120 PRINT " 1 , MI (K);", ";M2 (K); ", " ;M3 (K)

2130 RETURN 


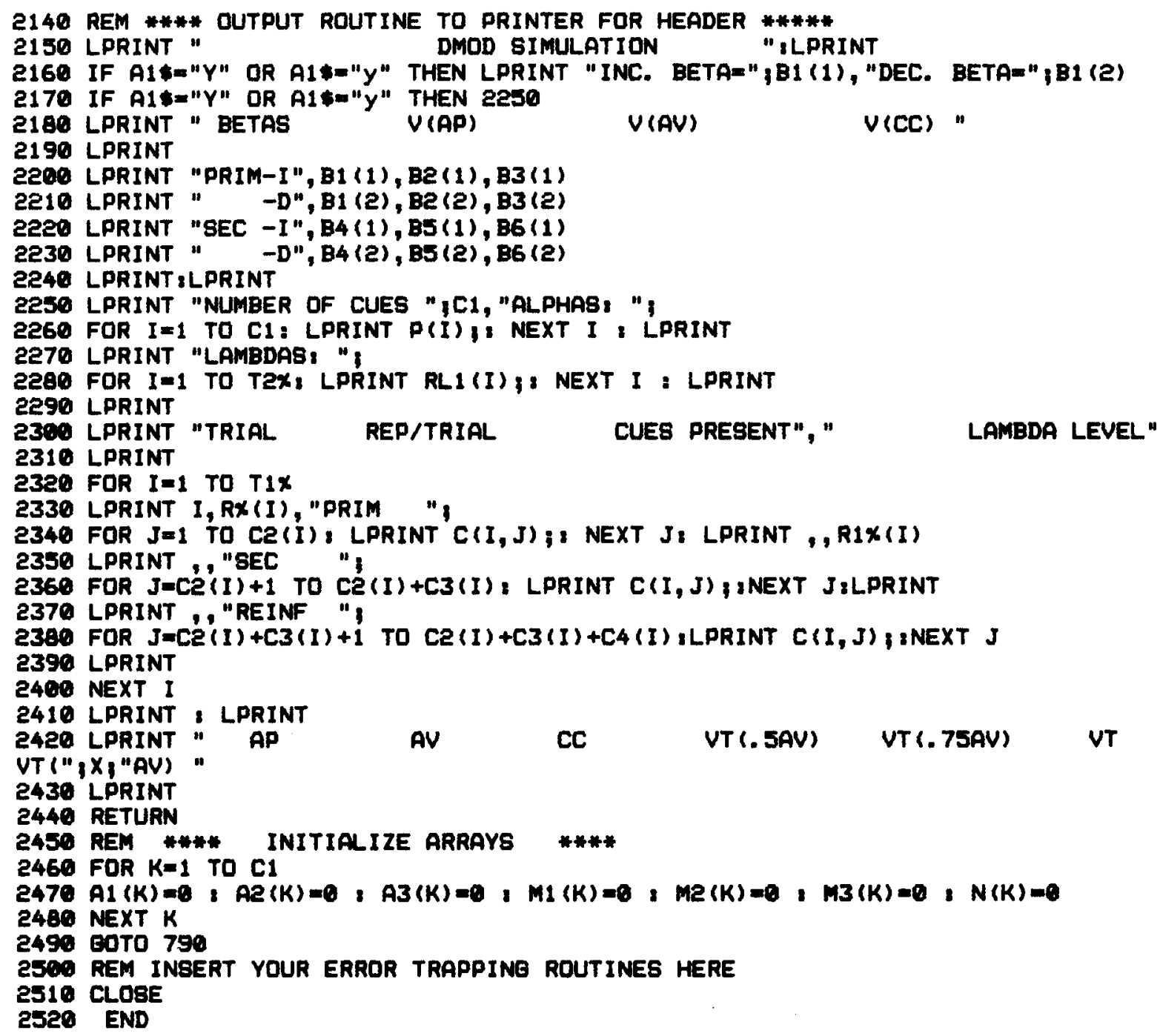

Note-The format of the input and output routines was adapted from a programmed version of the Rescorla-Wagner (1972) model written by Penn Pfautz. The size of the program is $12 K B$. If you have insufficient memory, then you should delete all remarks first. Next, you can delete the separate printer output lines (1930-1980, 2060-2090, 2140-2440). The file output may also be deleted without affecting the running of the program (1790-1860, 1990-2050, 2100-2130). 